DOI 10.37882/2223-2982.2020.05.07

\title{
АНАЛИЗ ПОКАЗАТЕЛЕЙ РЕЗУЛЬТАТОВ ПЛАВАТЕЛЬНОЙ ПОДГОТОВКИ ВАТЕРПОЛИСТОВ НА НАЧАЛЬНОМ ЭТАПЕ ОБУЧЕНИЯ ПО МЕТОДИКЕ ПОЛНОГО ПОГРУЖЕНИЯ ЗАНИМАЮЩИХСЯ В РАЗНОЕ ВРЕМЯ СУТОК
}

\section{ANALYSIS OF INDICATORS OF THE RESULTS OF SWIMMING TRAINING OF WATER POLO PLAYERS AT THE INITIAL STAGE OF TRAINING ACCORDING TO THE METHOD OF COMPLETE IMMERSION OF STUDENTS AT DIFFERENT TIMES OF THE DAY}

\section{Bondarenko}

Summary: Research in the field of swimming training of water polo players in the history of water polo in Kazakhstan is not conducted, there is no systematization of statistical indicators of the past and present Kazakhstan water polo. We were not able to find in the available scientific, methodological and fiction literature, sufficiently complete, statistical reference data that could characterize the development and current state of Kazakhstan's water polo.

One of the many main factors of a successful sports career in team game sports in general, and in water polo in particular, is modern, timely and optimal, in terms of the conditions of work and the capabilities of the athlete. But without a high level of swimming training, the location of the players on the field will not be of great importance.

Keywords: water polo, water polo player, technique, indicators, initial stage, training, preparation, ball, water polo crawl.

\author{
Бондаренко Вячеслав Александрович, \\ аспирант, Уральский государственный университет \\ физической культуры \\ BondarenkoV.Al@yandex.ru
}

Аннотация: Исследования в области плавательной подготовки ватерполистов в истории водного поло в Казахстане не проводятся, нет систематизации статистических показателей прошлого и настоящего Казахстанского водного поло. Нам не удалось найти в доступной нам научно-методической и беллетристической литературе, достаточно полных, статистических справочных данных, которые могли бы охарактеризовать развитие и современное состояние Казахстанского водного поло.

Один из многих главных факторов успешной спортивной карьеры в игровых командных видах спорта в целом, и в водное поло в частности является современный, своевременный и оптимальный, с точки зрения условий деятельности и возможностей спортсмена. Но без высокого уровня плавательной подготовки расположение игроков на поле большого значения иметь не будет.

Ключевые слова: водное поло, ватерполист, методика, показатели, начальный этап, обучение, подготовка, мяч, ватерпольный кроль.

\section{Введение}

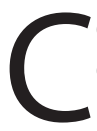
овременная спортивная деятельность ватерполиста предъявляет высокие требования к спортсмену [1, с. 19; 2, с. 8].В стремлении соответствовать этим требованиям многие тренеры стараются больше тренировать, считая, что чем больше тренируется его команда, тем лучше выступят в очередных играх [4, с. 148]. Однако, спортсмен, который тренируется все больше и больше, в конце концов увидит, что его результаты не улучшаются, а наоборот, ухудшаются [3, с. 21].

В исследовании принимали участие дети (мальчики) двух групп по водному поло (экспериментальная группа № 1 - тренировались по методу «полного погружения» В первой половине дня (в 9:30), экспериментальная груп- па № 2 - тренировалась по методу «полного погружения» во второй половине дня (в 15:30)) [5, с. 21].

Исследование проводилось в бассейне специализированной детско-юношеской спортивной школы олимпийского резерва «Дельфин» водных видов спорта, при содействии плавательного клуба «Vertex» (товарищество с ограниченной ответственностью «Арена СК»). В двух группах, по водному поло начальной подготовки состоящих из 24 человек (в каждой группе по 12 детей).

Средние показатели результатов тестирования трех срезов экспериментальной группы № 1 занимающиеся по методике «полного погружения» представлены в таблице 1. 
Таблица 1

Средние показатели результатов тестирования экспериментальной группы № 1

(по методике «полного погружения»)

\begin{tabular}{|l|l|l|l|l|}
\hline № & 50 м в/с (сек.) & $\begin{array}{l}50 \text { м ват. кр. } \\
\text { (сек.) }\end{array}$ & $\begin{array}{l}5 \times 3 \text { м в } \\
\text { створе ворот } \\
\text { (сек.) }\end{array}$ & $\begin{array}{l}15 \text { м ведение } \\
\text { мяча ват. кр. } \\
\text { (сек.) }\end{array}$ \\
\hline$\overline{\mathrm{x} 1}$ & $38,8 \pm 1,66$ & $45,38 \pm 1,93$ & $11,69 \pm 0,10$ & $11,57 \pm 0,12$ \\
\hline$\overline{\mathrm{X}} 2$ & $37,8 \pm 1,63$ & $44,43 \pm 2,0$ & $11,55 \pm 0,12$ & $11,44 \pm 0,13$ \\
\hline$\overline{\mathrm{x} 3}$ & $36,58 \pm 1,37$ & $42,85 \pm 2,25$ & $11,43 \pm 0,13$ & $11,31 \pm 0,14$ \\
\hline
\end{tabular}

Как видно из таблицы 1 на 1-ом, 2-ом и 3-ем срезах у экспериментальной группы № 1 занимающейся водным поло на начальном этапе обучения плавательной подготовке, которая занималась по методике «полного погружения» во второй половине дня (в 15:30), показатели на дистанциях: 50 м. вольный стиль (сек.), 50 м. ватерпольный кроль (сек.), $5 \times 3$ м. в створе ворот (сек.), 15 м. ведение мяча ватерпольным кролем (сек.) имеют положительную динамику. Полученные в ходе исследования результаты ватерполистов экспериментальной группы № 1 отличаются от результатов ватерполистов экспериментальной группы № 2.

Средние показатели результатов тестирования трех срезов экспериментальной группы № 2 занимающиеся по методике «полного погружения» представлены в таблице 2.

Таблица 2

Средние показатели результатов тестирования экспериментальной группы № 2

(по методике «полного погружения»)

\begin{tabular}{|l|l|l|l|l|}
\hline № & 50 м в/с (сек.) & $\begin{array}{l}50 \text { м ват. кр. } \\
\text { (сек.) }\end{array}$ & $\begin{array}{l}5 \times 3 \text { м в } \\
\text { створе ворот } \\
\text { (сек.) }\end{array}$ & $\begin{array}{l}15 \text { м ведение } \\
\text { мяча ват. кр. } \\
\text { (сек.) }\end{array}$ \\
\hline $\bar{x} 1$ & $39,78 \pm 0,86$ & $47,14 \pm 0,98$ & $11,82 \pm 0,08$ & $11,75 \pm 0,07$ \\
\hline $\bar{x} 2$ & $36,85 \pm 0,79$ & $43,63 \pm 1,28$ & $11,56 \pm 0,10$ & $11,5 \pm 0,10$ \\
\hline $\bar{x} 3$ & $35,34 \pm 0,70$ & $41,43 \pm 1,24$ & $11,34 \pm 0,11$ & $11,21 \pm 0,05$ \\
\hline
\end{tabular}

Как видно из таблицы 2 на 1-ом, 2-ом и 3-ем срезах у экспериментальной группы № 2 занимающейся водным поло на начальном этапе обучения плавательной подготовке, которая занималась по методике «полного погружения» в утреннее время (в 9:30), показатели на дистанциях: 50 м. вольный стиль (сек.), 50 м. ватерпольный кроль (сек.), $5 \times 3$ м. в створе ворот (сек.), 15 м. ведение мяча ватерпольным кролем (сек.) имеют положительную динамику. Полученные в ходе исследования результаты ватерполистов экспериментальной группы № 2 отличаются от результатов ватерполистов экспериментальной группы № 1 занимающейся по методике «полного погружения» во второй половине дня (в 15.30). Положительная динамика результатов отражается на втором и третьем срезах.
Сравнительный анализ средних показателей результатов тестирования на дистанции 50 метров вольным стилем трех групп по водному поло представлен в диаграмме 1.

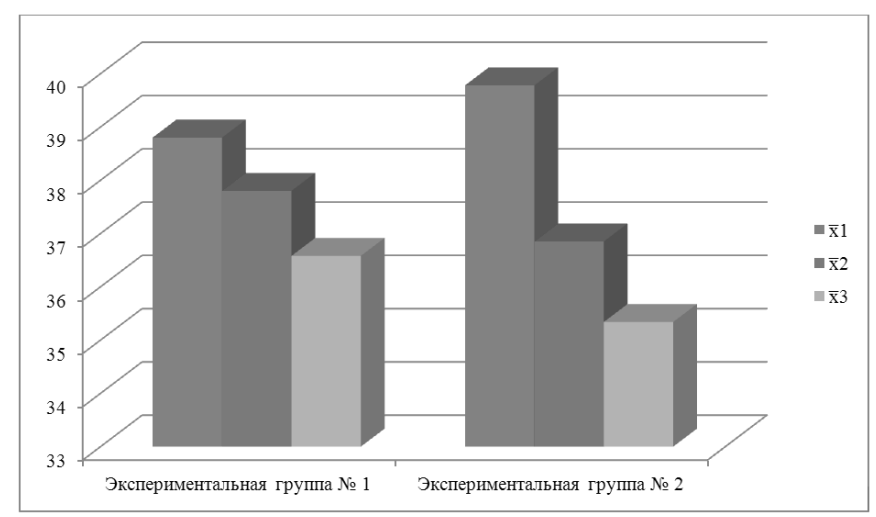

Диаграмма 1. Средние показатели результатов тестирования на дистанции 50 метров вольным стилем трех групп по водному поло

В диаграмме 1 представлены временные показатели, чем ниже столбец диаграммы - тем лучше время, затраченное на преодоление дистанции 50 метров вольным стилем. Из диаграммы видно, что время, затраченное на преодоление дистанции, при проведении каждого среза уменьшалось в двух группах по водному поло. Самый лучший средний временной показатель тестирования на 50 метров вольным стилем зафиксирован на третьем срезе у спортсменов, занимающихся в экспериментальной группе № 2, который равен (35,34 сек.), в экспериментальной группе № 1 результат составляет (35,58 сек.).

Сравнительный анализ средних показателей результатов тестирования на дистанции 50 метров ватерпольным кролем трех групп по водному поло представлен в диаграмме 2.

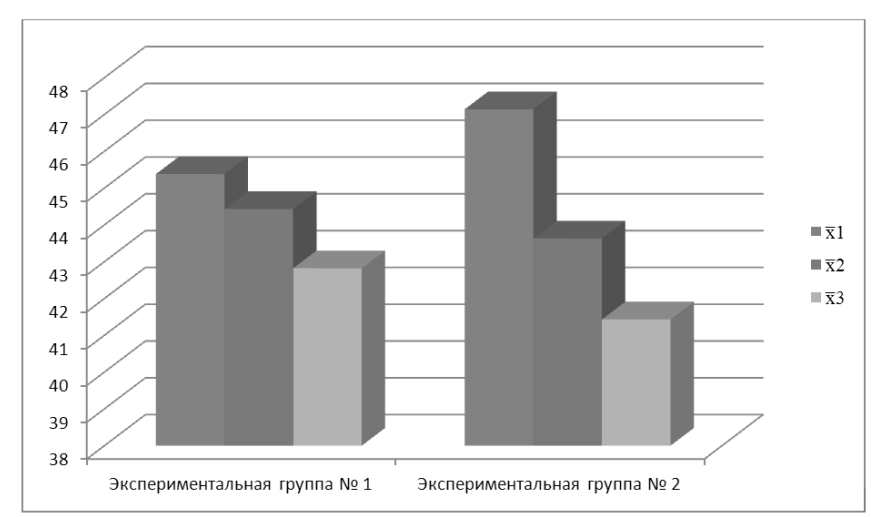

Диаграмма 2. Средние показатели результатов тестирования на дистанции 50 метров ватерпольным кролем трех групп по водному поло

В диаграмме 2 представлены временные показатели, чем ниже столбец диаграммы - тем лучше время, 
затраченное на преодоление дистанции 50 метров ватерпольным кролем. Из диаграммы видно, что время, затраченное на преодоление дистанции, при проведении каждого среза уменьшалось в двух группах по водному поло. Самый лучший средний временной показатель тестирования на 50 метров ватерпольным кролем зафиксирован на третьем срезе у спортсменов, занимающихся в экспериментальной группе № 2 (тренировки проходят в первой половине дня), который равен (41,43 сек.), в экспериментальной группе № 1 (тренировки проходят во второй половине дня) результат составляет $(42,85$ сек.).

Сравнительный анализ средних показателей результатов тестирования в упражнении $5 \times 3$ метра в створе ворот ватерпольным кролем трех групп по водному поло представлен в диаграмме 3.

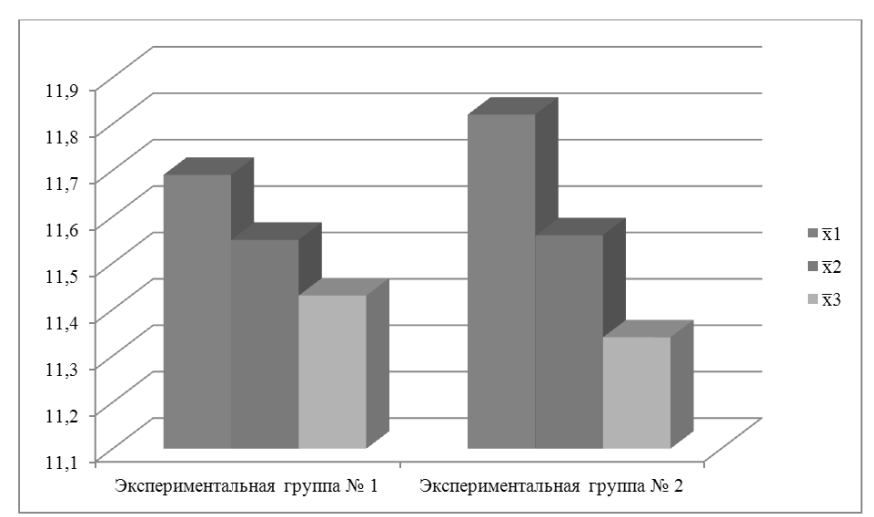

Диаграмма 3. Средние показатели результатов тестирования в упражнении $5 \times 3$ метра в створе ворот трех групп по водному поло

В диаграмме 3 представлены временные показатели, чем ниже столбец диаграммы - тем лучше время, затраченное на выполнение упражнения $5 \times 3$ метра в створе ворот ватерпольным кролем.

При проведении первого среза у экспериментальной группы № 1 по водному поло средний временной показатель был ниже (лучшее среднее время), на втором срезе картина стала меняться. Из диаграммы видно, что время, затраченное на выполнение упражнения ватерполистами, при проведении каждого среза уменьшалось в двух группах по водному поло. Самый лучший средний временной показатель тестирования упражнения $5 \times 3$ метра в створе ворот ватерпольным кролем зафиксирован на третьем срезе у спортсменов, занимающихся в экспериментальной группе № 2, который равен (11,34 сек.), в экспериментальной группе № 1 результат составляет $(11,43$ сек.).
Сравнительный анализ средних показателей результатов тестирования в упражнении 15 метров ведение мяча ватерпольным кролем трех групп по водному поло представлен в диаграмме 4.

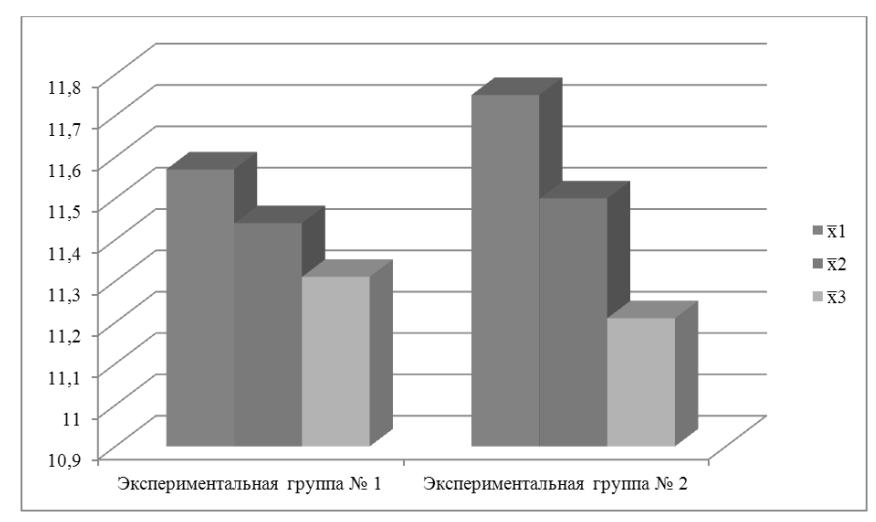

Диаграмма 4. Средние показатели результатов тестирования в упражнении 15 метров ведение мяча ватерпольным кролем трех групп по водному поло

В диаграмме 4 представлены временные показатели, чем ниже столбец диаграммы - тем лучше время, затраченное на выполнение упражнения 15 метров ведение мяча ватерпольным кролем.

Из диаграммы 4 видно, что время, затраченное на выполнение упражнения ватерполистами, при проведении каждого среза уменьшалось в двух группах по водному поло. Самый лучший средний временной показатель тестирования упражнения 15 метров ведение мяча ватерпольным кролем зафиксирован на третьем срезе у спортсменов, занимающихся в экспериментальной группе № 2, который равен (11,21 сек.), в экспериментальной группе № 1 результат составляет (11,31 сек.). Разница во временных показателях не большая, но для данного упражнения существенная.

\section{Зак^ючение}

Полученные данные расширяют и углубляют представления об оптимальной методике плавательной подготовки в водном поло, повышают эффективность научно-методического обеспечения подготовки ватерполистов. В целом, результаты позволили констатировать, что под влиянием систематических занятий по методике «полного погружения» у занимающихся водным поло в утреннее время (9:30) на начальном этапе отмечалась выраженная положительная динамика временных показателей проплывания дистанций и выполнения упражнений. 


\section{ЛИТЕРАТУРА}

1. Бондаренко В.А., Пигалова Л.В. Сравнительный анализ нормативов начальной подготовки первого года обучения Российской Федерации и Казахстана по направлению водное поло / В. А. Бондаренко, Л. В. Пигалова // Современный ученый. 2019. № 3. С. 19 - 23.

2. Бондаренко В.А., Пигалова Л. В. Формирование социально одобряемых ценностных ориентаций у тренеров-преподавателей по водному поло // Моdеrn Humanities Success. 2019. № 5. C. 8 - 11.

3. Ибрагимова А.С., Тимакова Т.С., Трещалин С.С., Трещалин А.С. Влияние возраста и специфики вида спорта на свойства личности юных ватерполистов // Вестник спортивной науки. 2015. № 5. С. $21-25$.

4. Кельблер П.Ю., Заятинова И.М. Проблемы современного водного поло в России / П.Ю. Кельблер, И.М. Заятинова // Всероссийская научно-практическая конференция обучающихся и научно-педагогических работников: сб. трудов.- 2018.- Томск.- С. $148-151$.

5. Марьин И.С. Программа плавательной (технической) подготовки ватерполистов на этапе совершенствования спортивного мастерства / И.С. Марьин // Современные векторы развития образования: Актуальные проблемы и перспективные решения: сб. статей.- 2019.- Москва.- С. 90 - 93.

(с) Бондаренко Вячеслав Александрович (BondarenkoV.Al@yandex.ru).

Журнал «Современная наука: актуальные проблемы теории и практики»

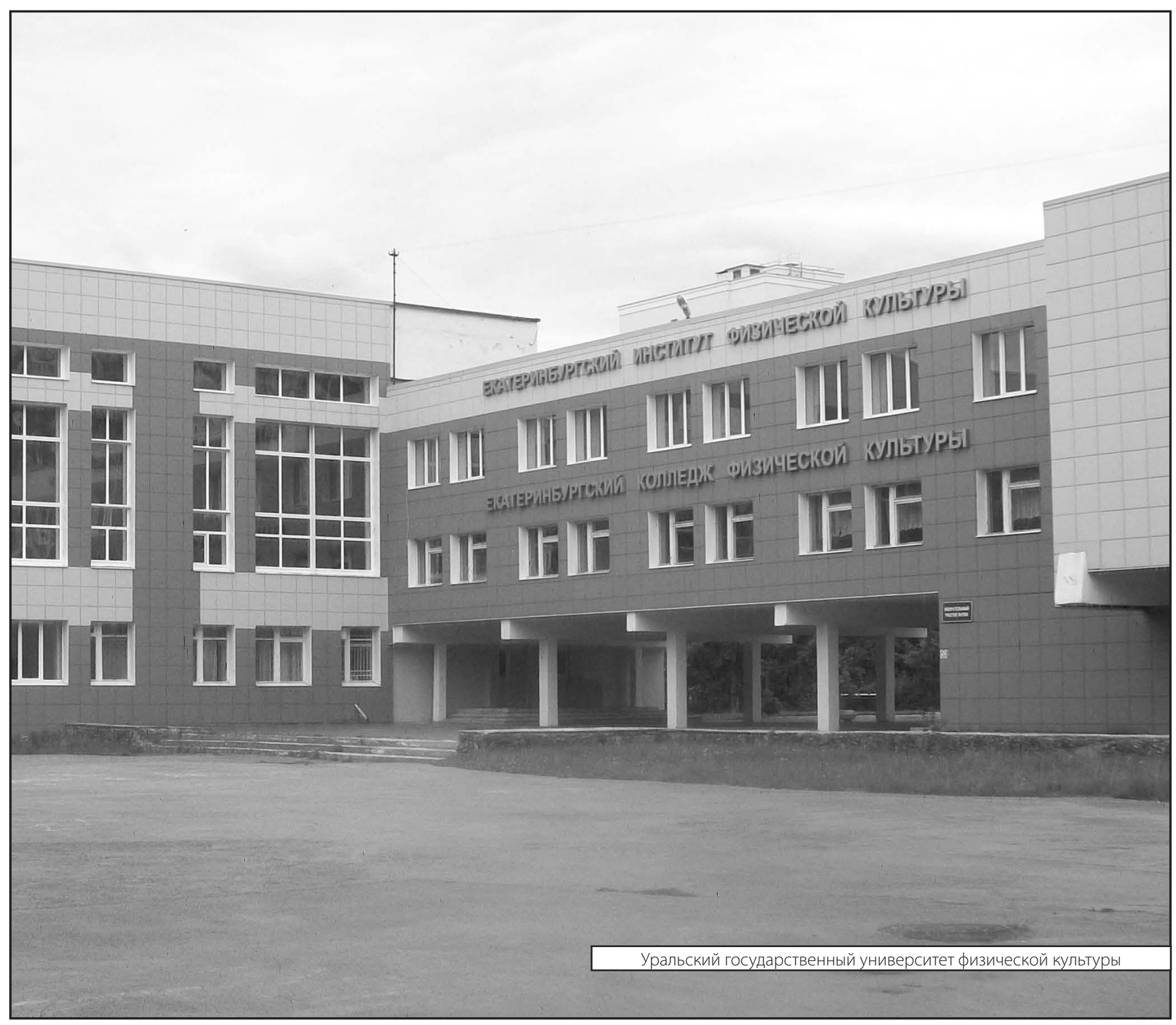

